among those in the rear of civilisation. However this may be, M. Pitre de Lisle has done good service to archæology in publishing his monograph upon this peculiar form of stone implement or weapon.

\section{INTERNATIONAL BUREAU OF WEIGHTS AND MEASURES}

UNDER the authority of the Comite International, representing several countries of Europe, the United States, and South America, there has been recently published, by Gauthier-Villars of Paris, an important volume of Memoirs by Dr. Broch (Directeur du Bureau, and Drs. Pernet, René-Benoît, and Marek (Adjoints du Bureau), on the following subjects relating to the determination of units of measure and weight.

As the intensity of weight varies with geographical position and height above level of the sea, the Comite give in their first memoir tables of the ratio of the acceleration of weight at the level of the sea, for different latitudes, to its acceleration at latitude $45^{\circ}$ (Paris), to which latitude the Comité recommend that all weighings might be referred. The tables are based on the formula of Laplace, the coefficients of which are corrected by Broch in accordance with recent deductions as to the figure of the earth. In the second memoir, which relates to the tension of aqueous vapour, certain corrections of hitherto accepted results are also indicated, particularly the errors of calculation in Regnault's tables as shown by Moritz, and new tables are given for tensions at all absolute barometer heights for normal degrees from $-30^{\circ}$ to + IOI $^{\circ} \mathrm{C}$.

With reference to the fixed points of mercurial thermometers, the Comite adopted the proposition that the point $0^{\circ}$ of the Centigrade thermometer should be fixed at the pressure of $760 \mathrm{~mm}$, when determined in $45^{\circ}$ latitude, and at the mean level of the sea. Also at the Congress of Meteorologists at Rome in 1879 there was adopted the proposition of Dr. Pernet, to fix the boiling point of water, $100^{\circ} \mathrm{C}$., under the above pressure, so as to render strictly comparable the temperatures observed at different places. Degrees of temperature between these points are termed normal-degrees.

Tables are also given, by which may be calculated the weight of a litre of pure air in different latitudes and at different altitudes. In London (lat. $=5 \mathrm{I}^{\circ} 30^{\prime}$, alt. $=6.7$ metres) the weight is $1 \cdot 293^{8}$ grammes. The Comite have adopted the term litre for expressing the volume of a kilogram of pure water, instead of the term cubic-decimetre.

In a report by $\mathrm{M}$. Herr on the Austrian unit of weight (Vienna, IS70), the volume of pure water at various temperatures is stated from the means of observations by Muncke, Stampfer, Kopp, and Pierre, the maximum density of water being taken at $3.92796 \mathrm{C}$. By this formula there have been calculated, under the directions of the Comité, tables of the volume and specific weight of water from $0^{\circ}$ to $30^{\circ} \mathrm{C}$.

One of the principal works executed during I878-9 was the comparisons of the standard kilograms at Vienna, Paris, and London. An elaborate report on these comparisons is given by M. Marek, who, by improved methods and instruments, has obtained great accuracy. The probable error of his weighings is about $0^{\circ} 002 \mathrm{mgr}$. or $1-500,000,000$ th part of the whole weight. The results also show that the material of which the standards are made, 90 per cent. of platinum and ro per cent. of iridium, is of all known bodies the least affected by time or atmospheric changes.

In a paper on Fizeau's apparatus for determining the rates of expansions of bodies by heat, by means of an optical method founded on the phenomena of interference, Dr. Benoit gives the results of his own experiences with a similar apparatus. The results show the wonderful deli- cacy of Fizeau's dilatometer, as the expansions by heat of small specimens of platinum are shown in a manner incontestable to millionths of a millimetre (o 00000004 inch).

An interesting account of the establishment and objects of the Bureau is given in a preface to this volume by the Secretary to the Comité, Dr. Ad. Hirsch ; and it is hoped that the efforts made by the Comite to bring about international agreement on the scientific points above referred to will commend themselves to all engaged in accurate work.

H. J. CHANEY

\section{A MODEL PUBLIC LIBRARY}

FNGLISHMEN are fond of descanting upon the evils of too much centralisation, which they see displayed in some foreign systems of government, urging the amount of red tape rendered almost necessary, its inflexibility, and lack of adaptation to the infinitely-varying circumstances of different communities. But, on the other hand, the extravagant cost of working every undertaking by a separate organisation, especially in a community not large enough to make such undertakings great matters, must come forcibly home to many of those who are naturally selected to work upon several.

There has lately come under our notice an admirable case of a public library avoiding this waste, securing all the energy of private zeal, and at the same time increasing the working power of it by becoming, as a public library should become, the centre of all secondary education and the parent stem of many and various branches. If any of the smaller towns of England feel that a free library would not in their case stand by itself on account of small income, we commend this to their notice as a specimen of the advantages of co-operation.

Watford has a population of about 10,000, and the penny rate on last year's gross rental of $34,589 l$. brought in $144 l .2 s$. Yet this small amount has developed round it an expenditure of $700 \%$ a year, equal to five times the largest rate collected, besides a large outlay on buildings at the beginning, costing some $3000 \%$. subscribed, in addition to the gift of the land. Ten distinct sections are worked in connection with it. The accounts of each are shown in a separate balance-sheet each year, and the agenda paper, with notice of committee-meetings, shows how methodically the work of each section is carried out and overhauled.

Section A, the Library proper, contains about 7000 volumes ; a payment of three shillings a year, or fourpence a month, is required for taking books home to read; the yearly issues accordingly amount to about 12,000. The only free part of the library, the reading-room, shows a something similar use of books; it is patronised chiefly by young men in the winter time, under the arrangements of Section D. The small subscription enables the book committee to spend about $50 \%$. a year in new books; magazines and periodicals being supplied by a separate club, connected, of course, with the institution. We should be glad to see the troublesome and irksome system of guarantors dropped. Towns which have freed themselves from the labour and annoyance they entail, though containing far larger proportions of the "great unknown" than can a place of the size of Watford, have found no evil result. The subscription also, though small, seems to render it less necessary here.

Section B is the School of Science and Art, the latter division showing clearly that the public library at Watford by no means attends to the wants of the industrial classes only, for non-Government pupils may pay six guineas a year for drawing only. For the benefit of the evening classes, at which non-Government pupils pay a guinea and a half for the year's instruction, and Government students (whose income, that is, or parents' income, does not exceed $200 \%$. a year) half that, "the subjects are 